\title{
Bilayer Suspension Plasma-Sprayed Thermal Barrier Coatings with Enhanced Thermal Cyclic Lifetime: Experiments and Modeling
}

\author{
Mohit Gupta $^{1} \cdot$ Chamara Kumara $^{1} \cdot$ Per Nylén ${ }^{1}$
}

Submitted: 29 December 2016/in revised form: 19 May 2017/Published online: 6 July 2017

(c) The Author(s) 2017. This article is an open access publication

\begin{abstract}
Suspension plasma spraying (SPS) has been shown as a promising process to produce porous columnar strain tolerant coatings for thermal barrier coatings (TBCs) in gas turbine engines. However, the highly porous structure is vulnerable to crack propagation, especially near the topcoat-bondcoat interface where high stresses are generated due to thermal cycling. A topcoat layer with high toughness near the topcoat-bondcoat interface could be beneficial to enhance thermal cyclic lifetime of SPS TBCs. In this work, a bilayer coating system consisting of first a dense layer near the topcoat-bondcoat interface followed by a porous columnar layer was fabricated by SPS using Yttria-stabilised zirconia suspension. The objective of this work was to investigate if the bilayer topcoat architecture could enhance the thermal cyclic lifetime of SPS TBCs through experiments and to understand the effect of the column gaps/vertical cracks and the dense layer on the generated stresses in the TBC during thermal cyclic loading through finite element modeling. The experimental results show that the bilayer TBC had significantly higher lifetime than the single-layer TBC. The modeling results show that the dense layer and vertical cracks are beneficial as they reduce the thermally induced stresses which thus increase the lifetime.
\end{abstract}

Chamara Kumara

chamara.kumara@hv.se

Mohit Gupta

mohit-kumar.gupta@hv.se

1 Department of Engineering Science, University West, 46186 Trollhättan, Sweden
Keywords bilayer coating system - finite element modeling $\cdot$ lifetime $\cdot$ suspension plasma spraying $\cdot$ stresses . thermal barrier coatings

\section{Introduction}

Thermal barrier coatings (TBCs) are widely used in the gas turbine industry to protect the metallic components from the high temperature environment. They also allow the turbine to operate in higher temperature so that turbine will run with increased efficiency (Ref 1 ). These coatings are applied by either thermal spraying or electron beamphysical vapor deposition (EB-PVD). Among the family of the thermal spraying, suspension plasma spraying (SPS) is a relatively new method for applying TBCs. Unlike the conventional thermal spraying methods where feedstock size is typically in the range of several micrometers, submicron and nano-sized particles can be used in SPS in the form of a suspension (Ref 2,3). SPS can be used to create a strain tolerant columnar microstructure similar to EB-PVD coatings at a fraction of the cost of EB-PVD coatings. The columnar microstructure fabricated by SPS typically contains much higher porosity than EB-PVD coatings and therefore, SPS TBCs exhibit lower thermal conductivity (Ref 4, 5) than conventional TBCs produced by atmospheric plasma sprayed (APS) and EB-PVD (Ref 6, 7). However, the lifetime of SPS TBCs under thermal shock loading is still an issue as the highly porous microstructure produced by SPS is prone to detrimental cracking.

Failure of TBCs is driven by several parameters. During service conditions, TBCs undergo thermal cyclic loading due to the cyclic variation of the environment temperature and the different thermal expansion coefficients of the layers in the TBC system. During start up and shut down of 
the turbine engine, thermal shock loading is generated which creates stress variations that cause the coating failure. The highest stresses typically occur near the topcoat (TC)-bondcoat (BC) interface during thermal cycling, thus causing failure of the coating near the TC-BC interface (Ref 8, 9).

It has been observed in previous work done by Viswanathan et al. (Ref 10) on APS coatings that TBC lifetime can be enhanced by (1) increasing the toughness of the topcoat near the TC-BC interface, and (2) increasing the compliance of the ceramic coating. The reason for increasing the toughness near the TC-BC interface is that this area is most prone to detrimental cracking as discussed above, while higher compliance would imply higher strain tolerance and thermal shock resistance during thermal cycling.

Toughness of the coating near the TC-BC interface could be increased either by spraying a graded coating with denser microstructure near the interface and porous microstructure toward the surface or by depositing a bilayer topcoat with first a dense layer with high toughness and then a conventional porous/vertically cracked layer. Since a graded microstructure increases the complexity of spraying, a bilayer coating architecture with a dense topcoat layer near the topcoat-bondcoat interface which could provide the necessary toughness followed by a strain tolerant layer for high lifetime seems to be a feasible approach. The appropriate thickness of the dense layer in a bilayer system for high lifetime was considered to be 50-60 $\mu \mathrm{m}(\operatorname{Ref} 10)$.

The compliance or strain tolerance of the coating is typically enhanced by spraying a vertically cracked microstructure by APS or a columnar microstructure by EB-PVD. A columnar microstructure produced by SPS would, however, be more suitable as the second layer in the bilayer topcoat as it provides both high strain tolerance as well as low thermal conductivity as discussed above. Fan et al. (Ref 11) investigated the effect of periodic vertical surface cracks on failure in TBCs and concluded that surface cracks with appropriately high density can enhance the durability of TBCs, which indicates that a columnar microstructure with periodic vertical column gaps similar to vertical surface cracks could be beneficial as the second layer in bilayer system to suppress interface cracks and thus enhance TBC lifetime.

The objective of this work was to investigate if the bilayer topcoat architecture could enhance the thermal shock lifetime of SPS TBCs and to understand the effect of the dense layer and the column gaps/vertical cracks on the generated stresses in the TBC during thermal cyclic loading. For this purpose, a bilayer coating system with a dense layer followed by a porous columnar layer was produced by SPS and compared to the single-layer SPS columnar coating system. A finite element model of the thermal shock test was developed to evaluate the induced thermal stresses in the two TBC systems.

\section{Experimental Details}

\section{Material and Process}

In this study, two TBC systems were sprayed-a singlelayer topcoat TBC and a bilayer topcoat TBC. The bilayer TBC consisted of a dense topcoat layer near the topcoatbondcoat interface which could provide the necessary toughness followed by a porous columnar layer which could provide the necessary strain tolerance for high lifetime. The single-layer TBC consisted of only the porous columnar layer as the topcoat.

8 wt.\% Yttria-stabilised zirconia (YSZ) ethanol suspension (Treibacher AG, Austria) with D50 = 500 nm and $25 \mathrm{wt} . \%$ solid load was used as the topcoat material in both cases to spray the columnar layers. The denser layer in the bilayer topcoat system was sprayed using the 8YSZ nano-suspension (Treibacher AG, Austria) with D50 $=50 \mathrm{~nm}$ and $25 \mathrm{wt} . \%$ solid load. The topcoat layers were deposited by Mettech Axial III SPS (Northwest Mettech Corp., Canada). Same spray parameters were used to produce the porous columnar layers in both topcoat systems while the dense layer of the bilayer system was obtained by changing the spray parameters as well as the suspension feedstock. The total target thickness for topcoats was $250 \mu \mathrm{m}$. In the bilayer system, the target thickness of denser layer was $50-60 \mu \mathrm{m}$, the porous columnar layer thickness thus being around $200 \mu \mathrm{m}$.

The bondcoat and substrate materials for both cases were NiCoCrAlY and Hastelloy-X, respectively, and were kept the same in both topcoat systems. Bondcoat was deposited by M3 HVAF gun (Uniquecoat Technologies, USA) with AMDRY 386-2 (Oerlikon Metco, Switzerland) as the bondcoat material. The target bondcoats thickness was $200 \mu \mathrm{m}$. Substrates in dimensions $25.4 \mathrm{~mm}$ diameter $\times 6 \mathrm{~mm}$ thickness were used in this study.

\section{Thermal Shock Testing}

Thermal shock testing evaluates the coating's ability to withstand rapid cooling and heating during the service of the coating. It tests how a coating can handle the stresses generated due to thermal expansion mismatch of the topcoat and bondcoat, topcoat sintering and high thermal gradients. Unlike thermal cyclic fatigue (TCF) testing, growth of the TGO and its effects are less important in thermal shock testing due to the short cycle time (Ref 12).

Testing was conducted using the burner rig at GKN Aerospace, Sweden. In the testing, samples surfaces were 
Table 1 Dimensions of the topcoat in the models

\begin{tabular}{llcl}
\hline Crack condition & Model & Notation & Topcoat height, mm \\
\hline No cracks & Single layer & S1 & $0.229(\mathrm{a})$ \\
& Bilayer & B1 & DL $-0.063 \pm 0.005$ \\
& & & PL $-0.166 \pm 0.022$ \\
Crack length equal to height of the PL & Single layer & S2 & 0.229 (a) \\
& Bilayer & B2 & DL $-0.063 \pm 0.005$ \\
Cracks all the way to TC-BC interface & Single layer & S3 & PL $-0.166 \pm 0.022$ \\
& Bilayer & B3 & DL $-0.063 \pm 0.005$ \\
& & & PL $-0.166 \pm 0.022$ \\
\hline
\end{tabular}

(a)Single-layer coating height was taken as the sum of the average value of the DL height and the PL height heated rapidly to around $1300{ }^{\circ} \mathrm{C}$ and rear face temperatures of between 960 and $980{ }^{\circ} \mathrm{C}$ during $75 \mathrm{~s}$ and thereafter forced cooled using compressed air from the rear side for $75 \mathrm{~s}$. Samples were monitored at the end of each cycle by using a camera system. Failure of the coating was considered to be when $20 \%$ of the coating area spall off from the coating surface. Three samples of each coating were tested in this study.

\section{Microstructure and Thickness Measurements}

For microstructure examination, the specimens were first infiltrated in vacuum with epoxy and mounted to avoid damage during the subsequent cutting and grinding steps. Thereafter, the specimens were cut using a diamond saw, mounted again and polished using a standard procedure for ceramic coatings. Sample cross sections in as-sprayed condition as well as after burner rig testing were investigated by scanning electron microscopy (SEM) using a Hitachi TM3000 TableTop SEM.

High surface roughness of the columnar microstructure induces significant errors in thickness measurement of the coating using a screw gauge. Therefore, thickness of individual layers in the bilayer system was measured using optical microscopy for the modeling work. More than 100 measurements were taken across the cross section of the coating. The topcoat thickness of the single-layer TBC was kept the same as the total thickness of the two layers in bilayer TBC in the model for direct comparison of the modeling results.

\section{Finite Element Modeling}

In order to understand how the column gaps/vertical cracks (hereafter referred to as only vertical cracks) and the dense layer affect the thermal shock lifetime of the coatings, a two-dimensional (2D) finite element model of the thermal shock test was developed. The developed models were used to calculate the temperature distribution and thermal stresses during thermal shock testing. It should be noted here the purpose of this numerical modeling was not to exactly predict the lifetime of the coating, but to acquire an insight on how the vertical cracks and dense layer influence the thermally induced stresses in the coating that influence the lifetime of the coating.

\section{Model Description}

To understand the effect of the vertical cracks and the dense layer on the thermal shock lifetime, six models were created as described in Table 1. The first set (S1 and B1) of models contained no vertical cracks, the second set ( $\mathrm{S} 2$ and B2) contained vertical cracks only in the porous topcoat layer (PL), while the third set (S3 and B3) contained vertical cracks in both PL as well as the dense topcoat layer (DL). For all three sets, single-layer and bilayer topcoats were modeled to study the effect of the dense layer and vertical cracks individually in each case.

The geometries for these models were created by using Siemens NX version 9 (Siemens PLM Software, USA) CAD software. The TC-BC interface was modeled as a simple sinusoidal wave with $20 \mu \mathrm{m}$ amplitude and $100 \mu \mathrm{m}$ wavelength. Other dimensions were set to experimentally measured values of the TBC system as shown in Table 1 . The average values of the measured dimensions were used in the models. A schematic representation of the 2D models is shown in Fig. 1 and 2. The generated CAD models were imported into the ANSYS workbench 15.0 (ANSYS, Inc., Canonsburg, PA, USA) environment where the numerical simulations were carried out.

In order to calculate the thermal stresses, temperature distribution across the model should be evaluated. Thus, initially a transient thermal analysis was performed to obtain the temperature distribution in the models during thermal shock testing. Once the temperature distribution 


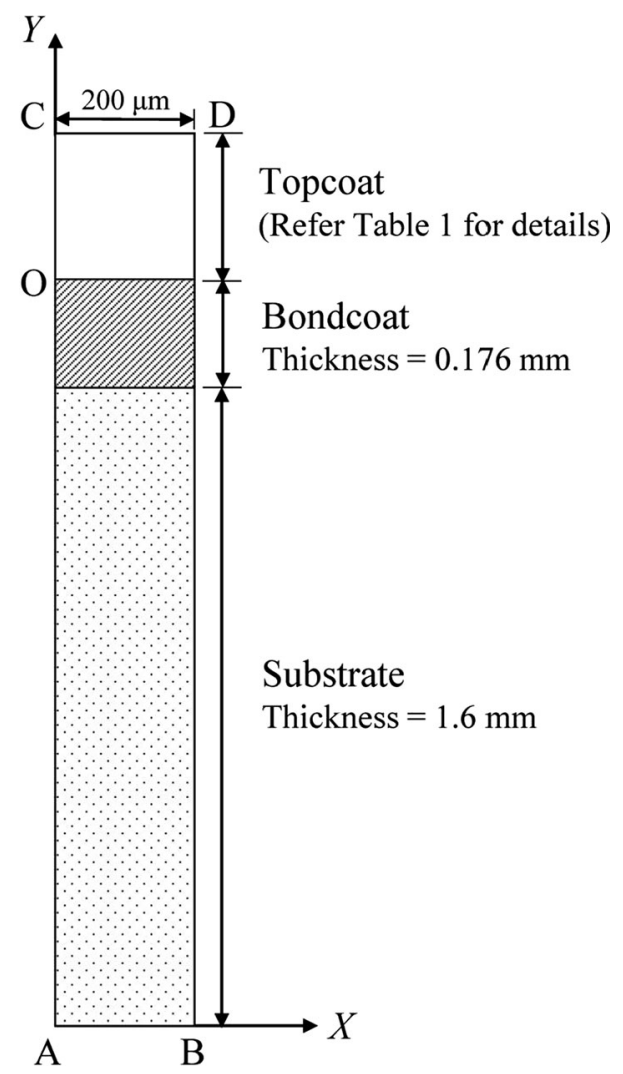

Fig. 1 Schematic representation of the model

was calculated, the results were imported into the static structural analysis module in ANSYS to evaluate the thermal stresses.

In transient thermal analysis, the following assumptions were made.

- Two-dimensional heat transfer occurred across the model.

- Oxidation of the bondcoat was neglected since it is typically not significant in thermal shock testing due to the short exposure time.

In the static structural analysis, 2D plane stress condition was used.

\section{Boundary Conditions}

In the transient thermal analysis, heat flux through the bottom and top boundaries $(\mathrm{AB}$ and $\mathrm{CD}$ in Fig. 1, respectively) of the model were adjusted in such a way that the temperature variation during the thermal shock cycling at the top and bottom boundaries of the model matches the measured temperature variation at the top and bottom of the samples. The boundaries AC and BD were kept insulated as it was assumed that there is no heat transfer in
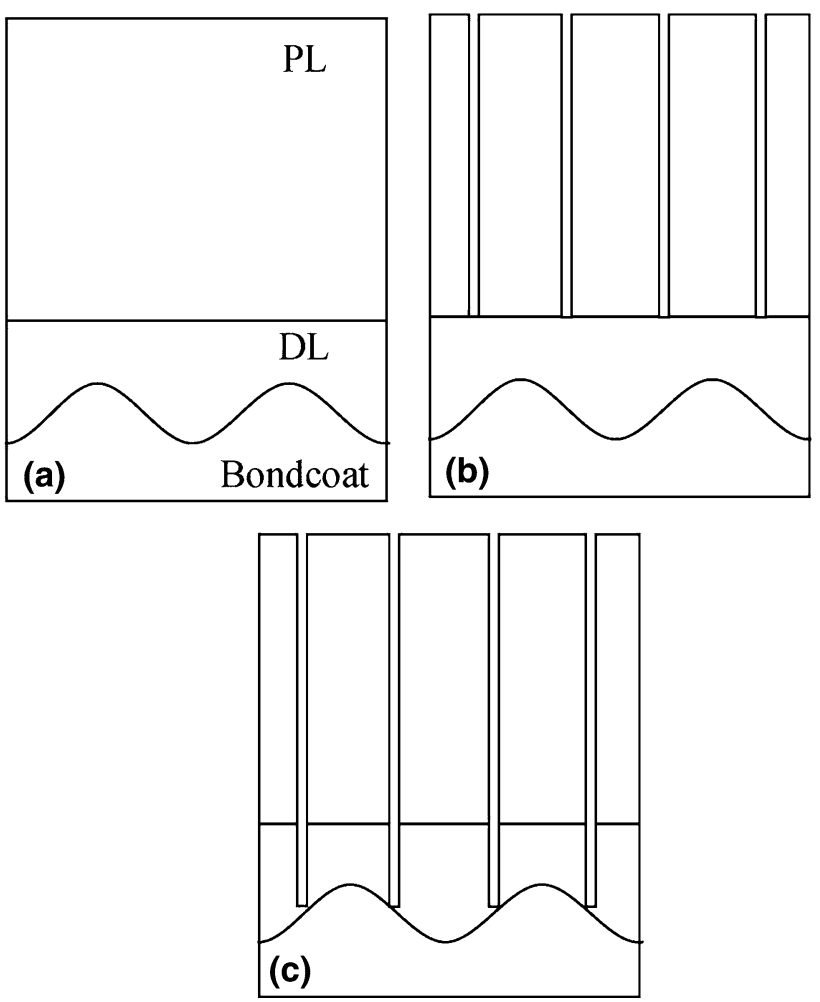

Fig. 2 Schematic representation of the topcoat geometry in the models; (a) no crack, (b) crack length equal to height of the PL, (c) cracks down to BC-TC interface

those directions because the specimens were much larger than the model geometry.

In the static structural analysis, following boundary conditions were assigned to the model geometry (refer Fig. 1).

- Bottom (AB) and Top (CD)—Free surface

- Left (AC)—No displacement along $x$ direction

- Right (BD)-Constrained displacement for all the nodes in the boundary so that the boundary moves keeping the shape as a straight line

- Point O-Fixed point

\section{Material Properties}

Temperature-dependent material properties were adapted from the available literature (Ref 13-18) for each material. Since the microstructure of the dense layer had less porosity value compared to the porous layer, higher values were selected for the relevant material properties of the dense layer than the porous layer. In the single-layer topcoat models, the topcoat was assigned the porous layer material property values. The material property values used in the models are listed in Tables 2 and 3. Norton power 
Table 2 Material property values of each layer at room temperature

\begin{tabular}{lcccc}
\hline Layer & Substrate & Bondcoat & Dense layer & Porous layer \\
\hline Young's modulus, GPa & 205 & 170 & 50 & 40 \\
Poisson's ratio & 0.32 & 0.31 & 0.2 & 0.2 \\
Density, kg/m & 8220 & 7400 & 5650 & 4000 \\
Thermal expansion coefficient, $10^{-6} / \mathrm{K}$ & 13 & 13 & 10 & 9.7 \\
Thermal conductivity, W/mK & 9.1 & 20 & 1.6 & 1.1 \\
\hline
\end{tabular}

Table 3 Creep property values

\begin{tabular}{lllll}
\hline Layer & Substrate & Bondcoat & Dense layer & Porous layer \\
\hline$A, \mathrm{~s}^{-1} \mathrm{MPa}^{-n}$ & 6000 & 1000 & 0.0001 & 0.0001 \\
$n$ & 5 & 3 & 3 & 3 \\
$C, \mathrm{~K}$ & 49,800 & 40,000 & 20,000 & 20,000 \\
\hline
\end{tabular}

law given in Eq 1 was used to calculate the creep data for the model:

$\dot{\varepsilon}=A \sigma^{n} e^{(-c / T)}$

where $\dot{\varepsilon}$ is the strain rate, $\sigma$ is the stress, $T$ is the temperature and $A, n$ and $c$ are material constants.

\section{Results and Discussions}

\section{Experimental}

\section{Microstructure}

SEM microstructure images of the single-layer TBC in assprayed condition are shown in Fig. 3. A porous columnar topcoat microstructure can be observed for the single-layer topcoat in Fig. 3(a). A thin crack can be observed along the topcoat-bondcoat interface which is deemed to occur during metallographic preparation of the sample. In Fig. 3(b), the column gap between the columns in the single-layer topcoat is shown at a higher magnification. It can be observed in Fig. 3(b) that the column gap, unlike a vertical crack in the conventional vertically cracked APS microstructure, is partially filled with mostly sphericalshaped particles and is also partially connected rather than a distinct gap as simulated in the finite element model. These particles could be formed due to overspray resulting from the deposition of particles which passed through the colder plasma plume periphery and were thus either not fully molten (Ref 19) or were solidified before impact on the substrate. The column gap in the case of single-layer topcoat shown in Fig. 3(b) was in the range of 12-15 $\mu \mathrm{m}$.

SEM microstructure images of the bilayer TBC in assprayed condition are shown in Fig. 4. A denser first layer

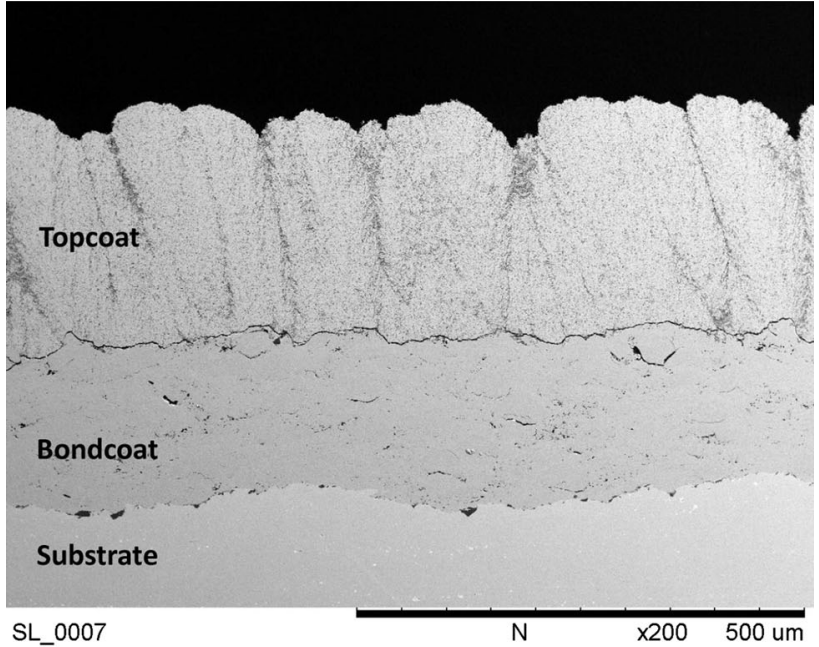

(a)

(b)

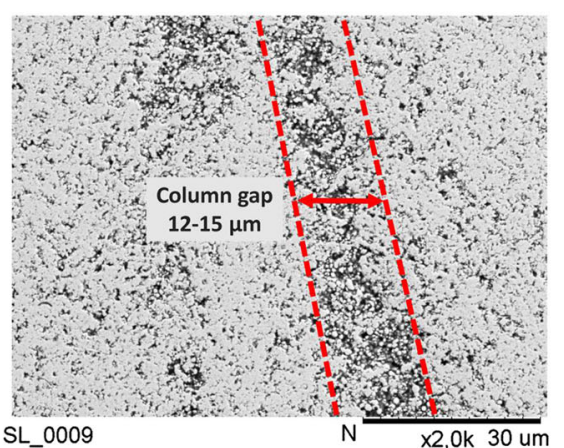

Fig. 3 Single-layer TBC SEM microstructure images in as-sprayed condition (a) an overview, and (b) column gap at a higher magnification

of topcoat can be observed in Fig. 4(a) which is followed by a porous columnar second layer similar to the topcoat in Fig. 3(a). In Fig. 4(b), the DL-PL interface is shown at a higher magnification along with the column gap in the PL. It can be observed in Fig. 4(b) that similar to the singlelayer topcoat shown in Fig. 3(b), the column gap is partially filled with semi-molten/unmolten particles and is also partially connected. The column gap in case of bilayer topcoat shown in Fig. 4(b) was in the range of $10-12 \mu \mathrm{m}$ which is lower than that of the single-layer topcoat. This could be due to the different roughness of the layer beneath (bondcoat in case of single-layer TBC while DL in case of bilayer TBC) which has been shown to strongly influence 

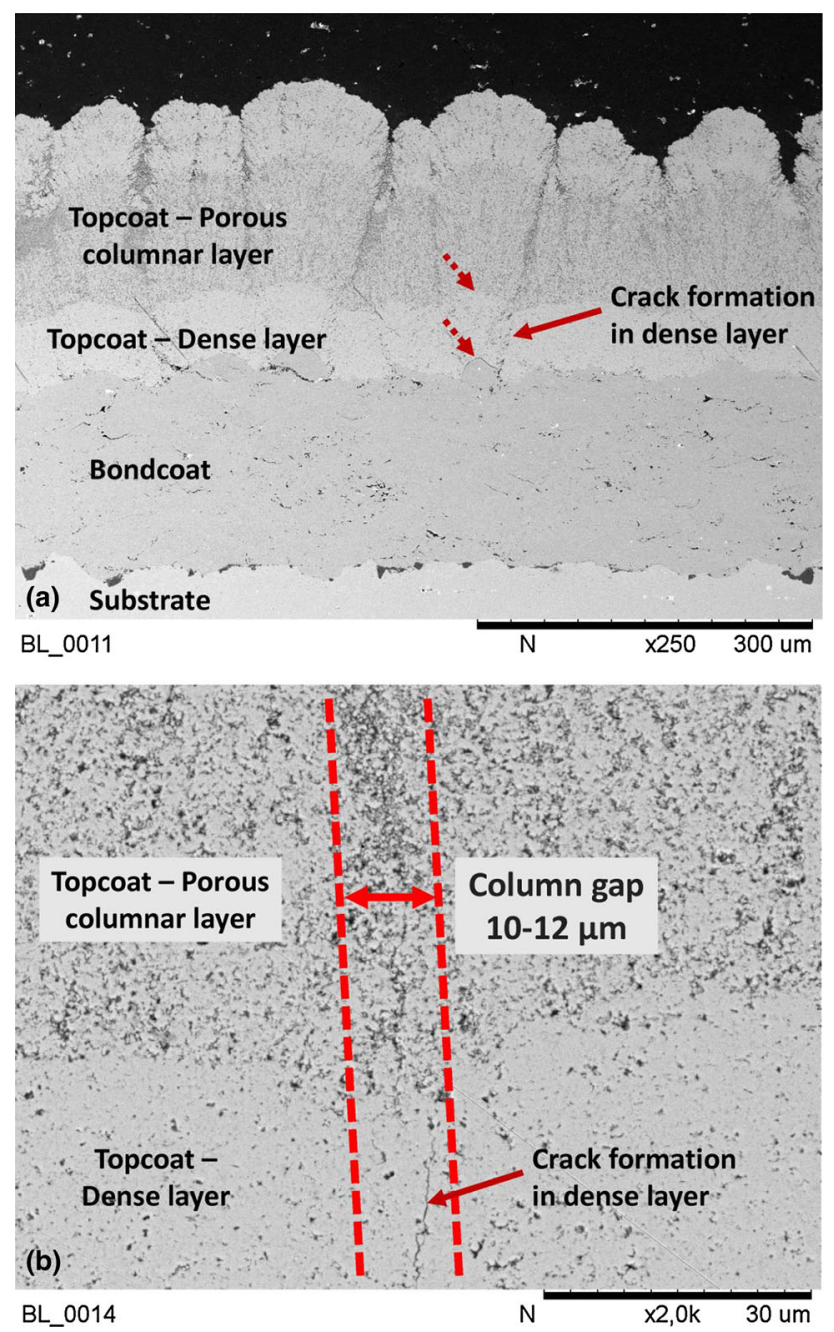

Fig. 4 Bilayer TBC microstructure in as-sprayed condition (a) an overview, and (b) the DL-PL interface at a higher magnification

the resulting topcoat microstructure and thus could result in different column gaps (Ref 12). It should be noted here that the column gap width was measured approximately as shown in the figures. Defining a column gap clearly in such a diffused structure is rather complex, and therefore, this interpretation should be considered only qualitatively.

Another feature which could be observed in Fig. 4(b) is the extension of the column gap from the PL into the DL in the form of a vertical crack. These vertical cracks were found to be more prominent near the surface asperities present in the bondcoat layer as indicated in Fig. 4(a). Marr et al. (Ref 20) showed in previous work done on SPS deposition of thin and dense YSZ coatings for solid oxide fuel cell applications that the surface asperities on the layer beneath could result in regions of aligned and concentrated porosity on their sides similar to the cracks observed in Fig. 4(b). This type of surface asperities is also deemed to be reason for the formation of a columnar microstructure as proposed by VanEvery et al. (Ref 21) and the column gaps

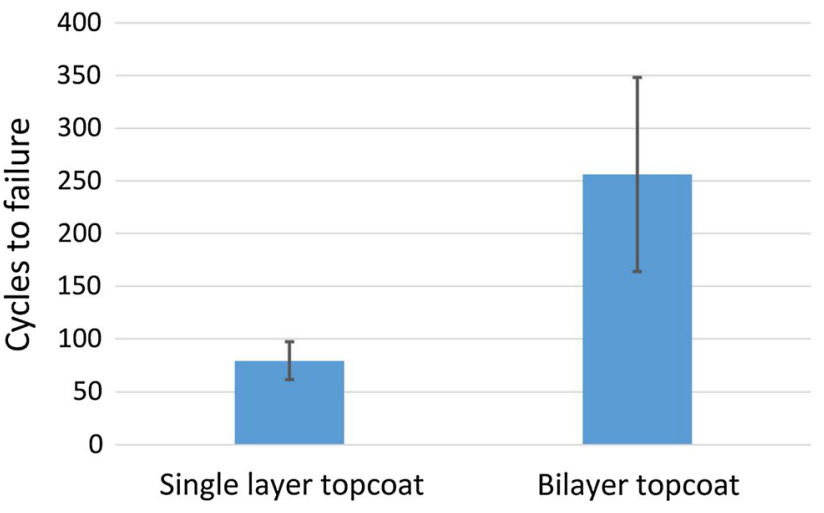

Fig. 5 Thermal shock testing lifetime results from experiments

are usually formed along the sides of these asperities. In Fig. 4(a), it can be observed the surface asperity on the bondcoat layer (indicated by dotted arrow) which resulted in the vertical crack in DL (indicated by the solid arrow) also resulted in a similar surface asperity on the DL (indicated by another dotted arrow) which could have promoted the column gaps along its sides. Therefore, this could explain why the columnar gaps in the PL are aligned with the vertical cracks in the DL .

In Fig. 4(a), an undesired feature can be observed that the porosity of the PL decreased toward the coating surface. The authors believe that the possible reason for this could have been that suspension might have not been well dispersed during spraying due to lower amount of suspension left toward the end of the spray run and therefore the solid load might have gone up from $25 \%$ during spraying resulting in a denser layer toward the top. Another reason could be the interruption during spraying to measure the thickness of the resulting layer in order to achieve the correct thickness as desired. However, this unintentional effect on the microstructure would not affect the results significantly.

\section{Thermal Shock Testing}

Figure 5 shows the thermal shock test lifetimes of the single-layer and bilayer TBC samples. It can be clearly seen that the bilayer topcoat had a significantly higher lifetime than the single-layer topcoat. Bilayer samples showed three times higher average lifetime than the singlelayer samples.

The microstructure of the single-layer TBC after failure in burner rig testing is shown in Fig. 6(a). It can be observed that failure occurred in the topcoat near the TC$\mathrm{BC}$ interface within approximately $50 \mu \mathrm{m}$ of the interface. This failure mode was expected as the highest stresses occur near the TC-BC interface as discussed in section "Introduction" and correlates well with other studies done 

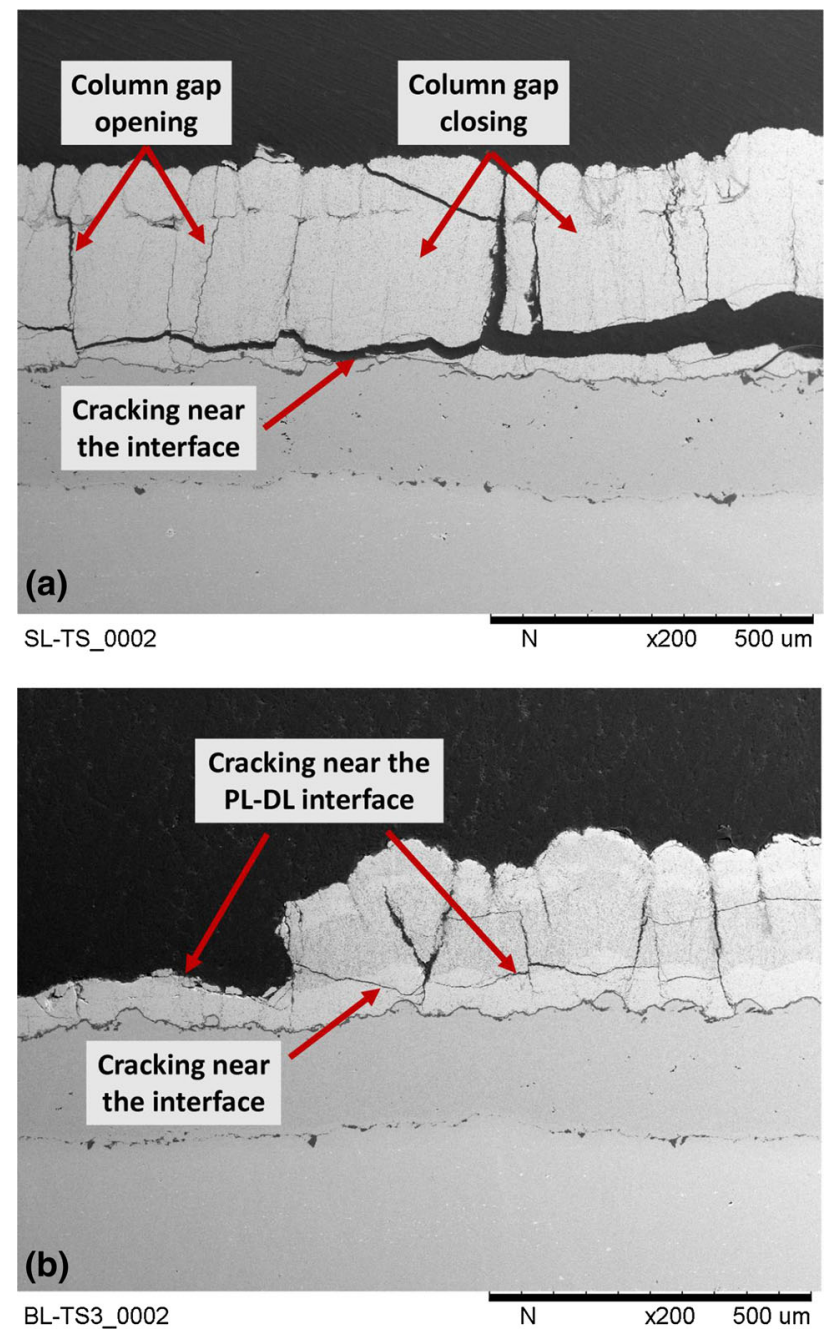

Fig. 6 (a) Single-layer TBC, and (b) bilayer TBC SEM microstructure images after failure in burner rig testing

on SPS coatings (Ref 22). Opening as well as closing of the column gaps in the topcoat due to thermal cycling and possible sintering effects was also observed as indicated in Fig. 6(a). The opening of column gap seemed to facilitate crack propagation within the topcoat in certain cases as shown in Fig. 6(a) which needs to be investigated further.

The microstructure of the bilayer TBC after failure in burner rig testing is shown in Fig. 6(b). In this case, the failure mode was a mixture of cracking in the topcoat (1) near the TC-BC interface and (2) close to the PL-DL interface. It seems from the results that the higher fracture toughness of the dense layer near the TC-BC interface prevented severe cracking and thus delayed the failure as previously observed for APS coating (Ref 10). The possible reasons for crack formation close to the PL-DL interface could be (1) lower adhesion of the two layers due to significantly different porosities, (2) lower fracture toughness of the PL as compared to the DL, and/or (3) lower thermal expansion coefficient of the DL due to lower porosity than the PL. This phenomenon was also observed in previous work done on multilayered multimaterial SPS coatings (Ref 22). A graded coating with denser microstructure near the TC-BC interface and porous microstructure toward the surface may solve these issues and further extend the bilayer TBC lifetime.

\section{Modeling}

\section{Thermal Analysis}

Figure 7 shows the temperature variation in the topcoat of the model S1 at the end of a heating cycle and a cooling cycle. The figure shows that a gradient temperature profile was achieved with values similar to the experimental values during burner rig testing. Similar temperature profiles were observed in the other models.

\section{Stress Variation During Thermal Cycling}

Figure 8 shows the $Y$ direction stress variation during thermal cycling in the model B1 at the end of 3rd heating cycle and 3rd cooling cycle. High tensile stresses can be observed near the peaks of the sinusoidal TC-BC interface at the end of the cooling cycle while at the end of the heating cycle, high tensile stresses can be observed near the valleys of the sinusoidal TC-BC interface profile. These stress patterns are similar to the observations in previous work which occur to the sinusoidal interface geometry and the thermal expansion mismatch between different layers in the TBC system (Ref 9,23). All models investigated in this study similar stress patterns and thus the results presented here will be focussed on these areas.

\section{Stress Variation with Time}

All models showed cyclic stress variation in the topcoat with time due to the cyclic heating and cooling of the samples under thermal shock testing environment. Figure 9 shows this variation of stresses in the $\mathrm{S} 1$ model at a single point close to a peak and a valley location of the TC-BC interface profile during the first four cycles. In Fig. 9, the first $75 \mathrm{~s}$ along the time axis shows the heating cycle while the next $75 \mathrm{~s}$ shows the cooling cycle and so on. Both near peak and near valley $X$ direction stresses increased initially during the heating cycle and then decreased during the cooling cycle. However, the growth in stresses during each heating cycle started to decrease with time due to the creep. The rate of decrease in the maximum stresses during each subsequent heating cycle due to creep was observed to be dying down (when considering the dotted curve that goes through the peak of the heating cycle stresses in Fig. 9(a)) 
Fig. 7 Temperature profile (in

${ }^{\circ} \mathrm{C}$ ) in the S1 model topcoat

(a) at the end of the heating

cycle, and (b) at the end of the cooling cycle
A: Transient Thermal

Temperature 2

Type: Temperature

Unit: ${ }^{\circ} \mathrm{C}$

Time: 75 2016-12-15 16:16

$1165,4 \mathrm{Max}$

$1165,4 \mathrm{Max}$
1149,4

1149,4
1133,5

1133,5

1101,7

1085,7

1069,8

1053,9

1038

1022.1 Min

(a)
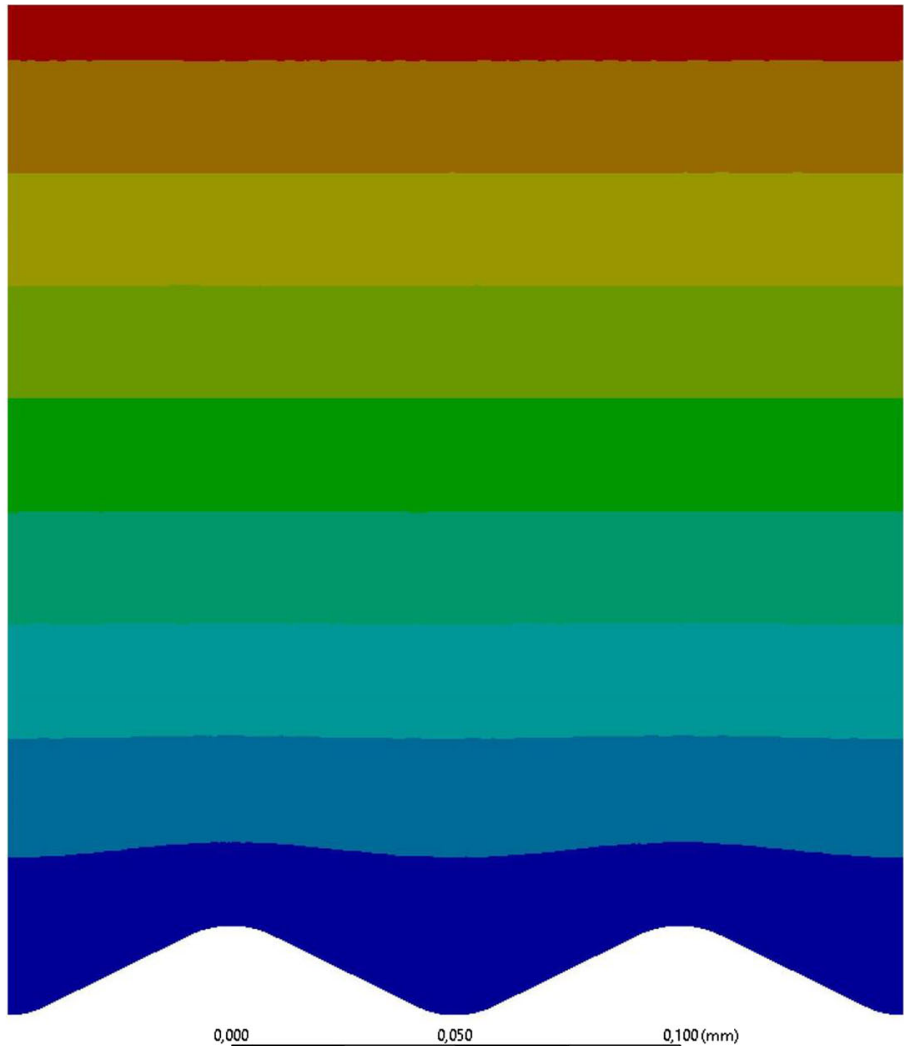

0,000

5

0,07

A: Transient Therm

Temperature 2

Type: Temperature

Unit: ${ }^{\circ C} \mathrm{C}$

2016-12-15 16:16

$355,78 \mathrm{Max}$

351,99

348,19

344,4

340,6

336,8

333,01

329,22

325,42

$321,63 \mathrm{Min}$

(b)
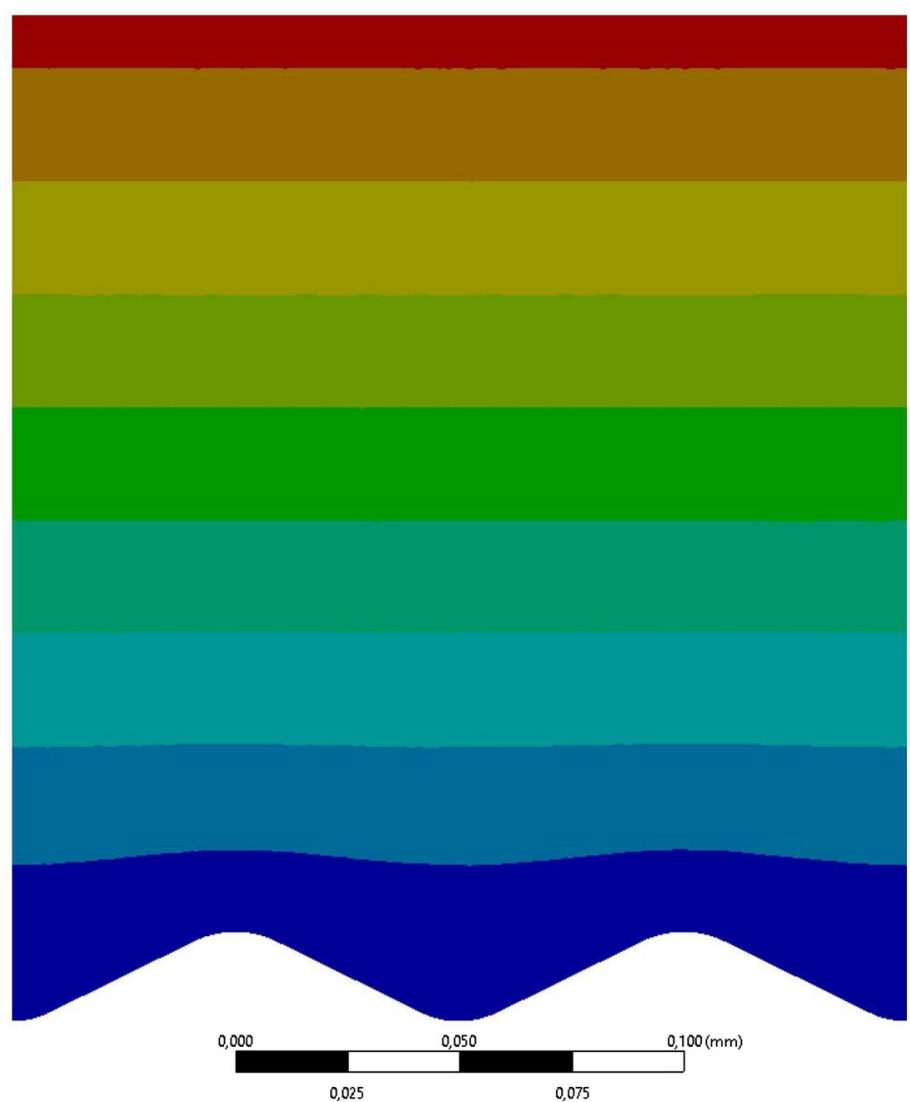
Fig. $8 \quad Y$ direction stress (in $\mathrm{MPa}$ ) variation during thermal cycling in the B1 model topcoat (a) at the end of the 3rd cooling cycle, and (b) at the end of the 3rd heating cycle
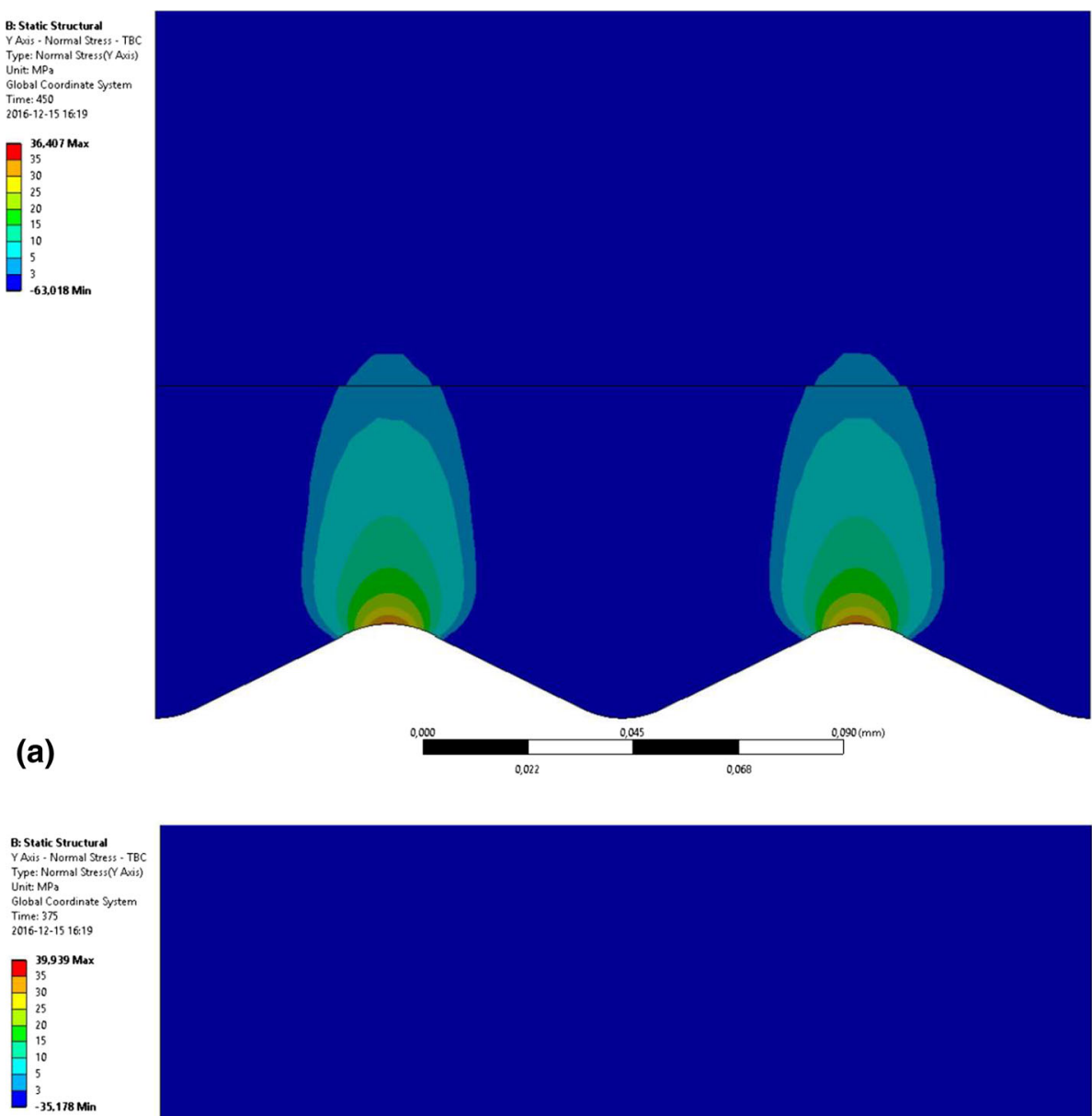

(b)

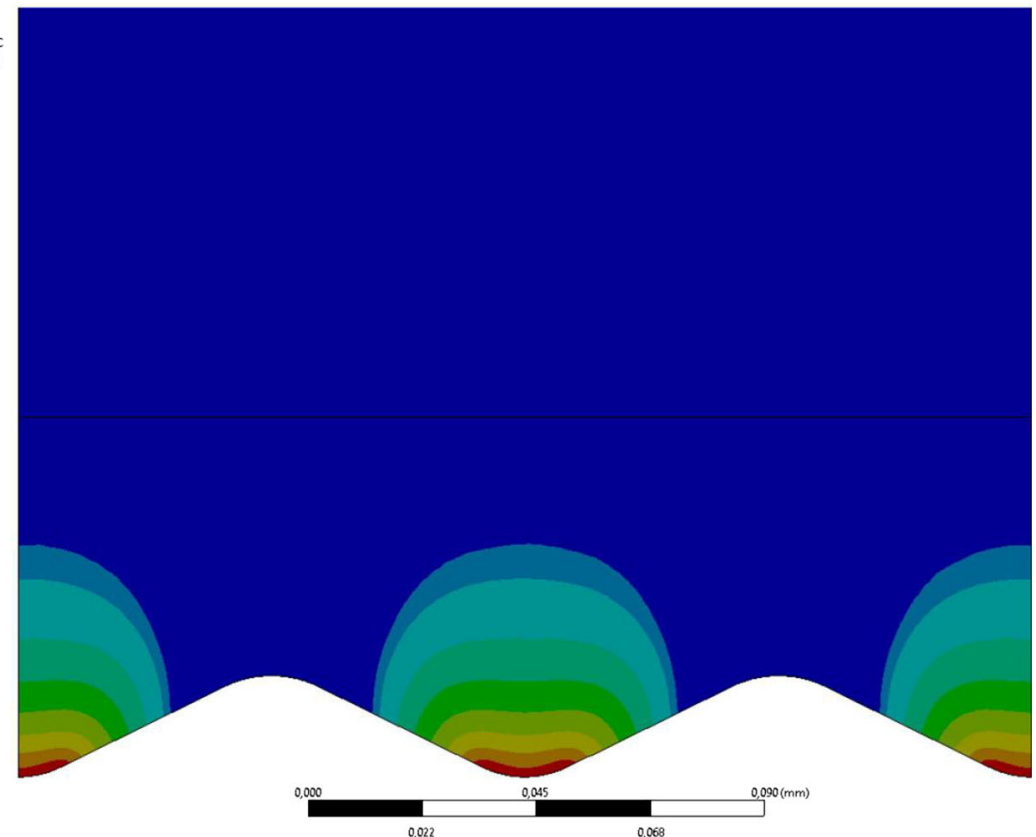

indicating the stress amplitude $\Delta \sigma$ (from tensile to compressive and vice versa) during heating and cooling will reach a steady state after a certain time.

The $Y$ direction stresses near the peak and valley location showed opposite variation to each other. Near peak $Y$ direction stress fluctuated from compressive stress during the heating cycle to tensile stresses during the cooling cycle whereas the near valley stresses fluctuated from tensile to compressive stresses from heating to cooling cycles. The reason for the two opposite $Y$ direction stress states in the peak and valley locations as in this case has been explained in previous work (Ref 16). Similar to the case for $X$ direction stresses shown in Fig. 9(a), both near peak and near valley $\Delta \sigma$ in case of $Y$ direction stresses also seem to be reaching a steady state after a certain time as indicated by the dotted curves. Similar stress variations with time were observed in other models in this study.

Stress relaxation can occur only during the heating cycle and no creep occurs during the cooling cycle because creep values are too low at lower temperatures. The $X$ direction stresses initially increase during the heating cycle in both near peak and near valley positions. During the cooling 


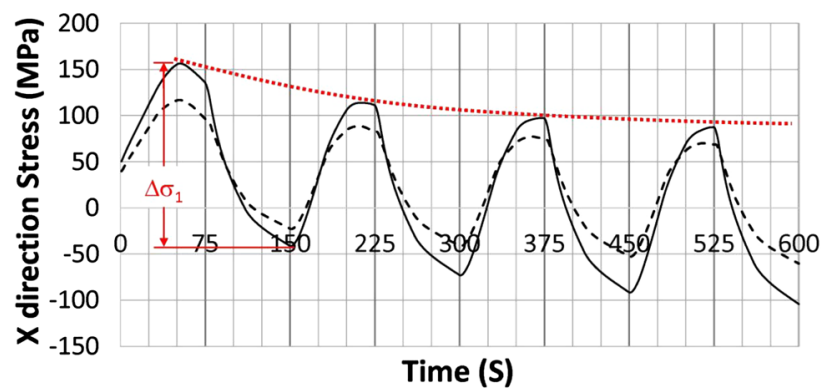

(a) —Near Peak ---Near Valley

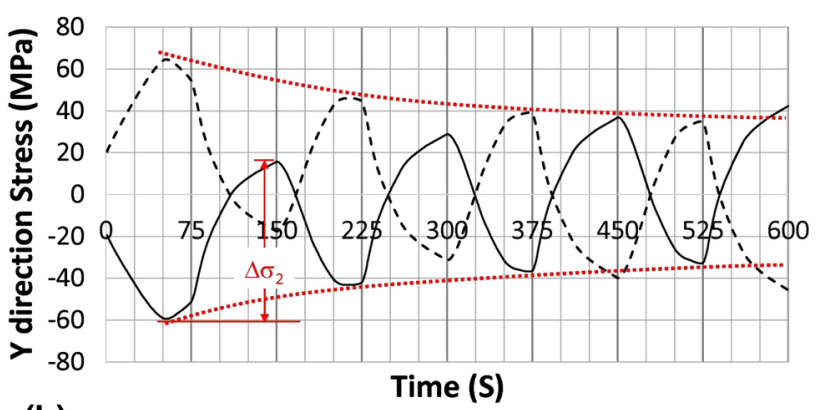

(b) —Near Peak ---Near Valley

Fig. 9 Stress variation with time in the $\mathrm{S} 1$ model at near peak and near valley locations along (a) $X$ direction, and (b) $Y$ direction

cycle, there will be no creep and there will be a constant level of reduction of stresses $\Delta \sigma_{1}$ from tensile to compressive as shown in Fig. 9(a). In the next heating cycle, due to the creep, the stresses will not reach the previous cycle maximum stress level even though the temperature rise is the same as previous cycle. However, since there is no creep during the cooling, stresses will decrease in the same amount $\Delta \sigma_{1}$ as previous cycle since the temperature reduction is same as the previous cycle.

Similarly, $Y$ direction near peak stresses initially decreases during the heating cycle. During the cooling, since there is no creep, the stresses will increase in a constant amount $\Delta \sigma_{2}$ from compressive to tensile as shown in Fig. 9(b). In the next heating cycle, stresses will not reach the minimum stress level as the previous cycle due to creep but during the next cooling cycle; there will be the same stress increase $\Delta \sigma_{2}$ since the temperature reduction is the same. Therefore, it will have a higher peak tensile stress value than the previous cycle peak stress value during cooling.

\section{Effect of Dense Layer on Coating Stresses}

Figure 10 shows the stress variations with time for the S1 and B1 models at the near peak location. It can be observed that the bilayer model B1 with a DL showed lower $\Delta \sigma$ in the topcoat during thermal cycling when compared to the similar single-layer model. The reason for this could be that since the DL had a higher thermal expansion
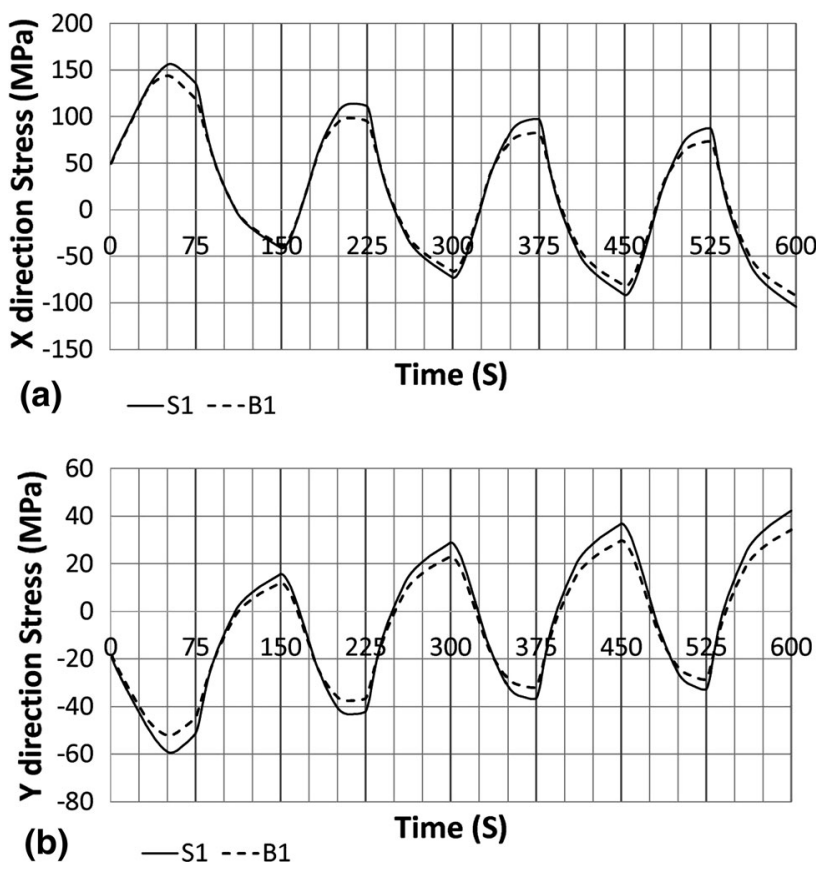

Fig. 10 Stress variation with time in S1 and B1 models near peak location along (a) $X$ direction, and (b) $Y$ direction

coefficient than the PL (see Table 2), the thermal expansion mismatch between the metallic bondcoat and the ceramic coating became lower. The lower thermal expansion mismatch in the bilayer model as compared to the single-layer model would reduce the stresses near the TCBC interface. Lower stresses near the TC-BC interface would imply lower detrimental cracking thus leading to longer lifetime, which could explain the experimental results in this study as well as previous work done on APS coatings (Ref 10) why the bilayer coatings exhibited significantly longer cyclic lifetime.

Other important phenomena which were not considered in the model in this study are fracture toughness. The initial driving force for crack propagation is high stress but the crack generation and propagation also depend on the material's fracture toughness. Higher fracture toughness of the DL was probably another factor leading to higher lifetime of the bilayer samples as observed in previous work done on APS coatings (Ref 10).

\section{Effect of Vertical Cracks on coating Stresses}

Figure 11 shows the stress variations with time for the $\mathrm{S} 1$ and S3 models at the near peak location. It can be clearly observed that the model S3 with vertical cracks down to the TC-BC interface showed much lower $\Delta \sigma$ in the topcoat during thermal cycling than model S1 with no vertical cracks along both $X$ - and $Y$ directions. Similar effect was observed when comparing the bilayer models B1 and B3. 

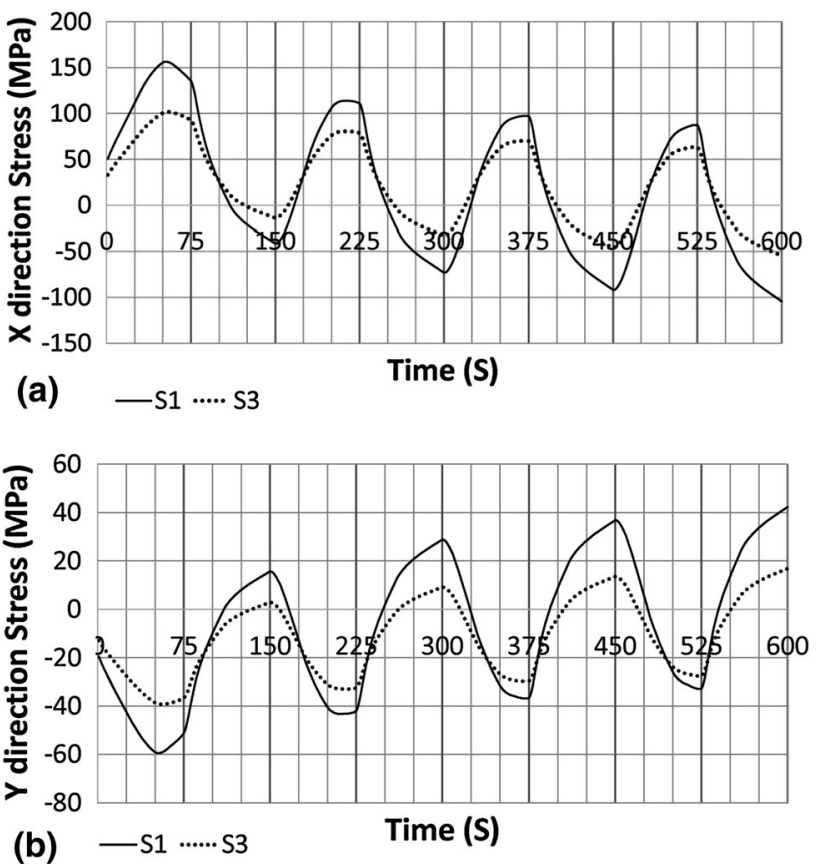

Fig. 11 Stress variation with time in S1 and S3 models near peak location along (a) $X$ direction, and (b) $Y$ direction

The difference in $\Delta \sigma$ between S1 and S2 near the peak and valley locations was observed to be very small. However, in the case of model S2, the stresses in the coating area where cracks were present showed compressive stresses which are not detrimental as shown in Fig. 12. Similar results were reported in the literature (Ref 24) for the $X$ direction stresses in the coating which imply that the vertical cracks increase the strain tolerance of the coating during thermal cycling.

These results show that vertical cracks are highly beneficial for reducing stresses in both $X$ direction thus providing better strain tolerance as well as $Y$ direction thus preventing the formation of detrimental cracks in the topcoat during thermal cycling.

\section{Stress Amplitude Versus Coating Lifetime}

During thermal shock testing, the stresses in the coating fluctuate from tensile to compressive or vice-versa due to the cyclic thermal loading resulting from the cyclic temperature variation. This fluctuation of the stresses will result in thermo-mechanical fatigue in the coating which will influence the lifetime of the coating. As proposed in the lifetime prediction model by Liu et al. $(\operatorname{Ref} 8)$, the coating's lifetime is dependent on $\Delta \sigma$. A higher $\Delta \sigma$ in the coating would imply a lower lifetime and vice-versa. Therefore, $\Delta \sigma$ could be a helpful parameter to understand the lifetime of the coatings and especially to compare different coatings. It must be noted here that the failure will significantly depend on if the mean stresses operate largely in tension or compression. In this case, since the coatings did not show a significant difference in the mean stresses, the stress amplitude would be the key factor. TBCs typically fail due to the horizontal crack propagation within the ceramic coating. The driving force for this is the $Y$ direction stresses generated in the topcoat, and thus $\Delta \sigma$ in $Y$ direction stresses was selected for comparison of the lifetime of different models.

Since higher $\Delta \sigma$ occurred in the areas above peak and valley locations, the $\Delta \sigma$ (here it is the difference between maximum and minimum stresses during the 3 rd cycle) with respect to the $Y$ direction distance from the TC-BC interface was investigated for these areas for all models.

Figure 13 shows $\Delta \sigma$ above a peak location in all models against the $Y$ direction distance from the peak at the TC-BC interface. All models showed higher $\Delta \sigma$ near the TC-BC interface indicating that failure or crack initiation can happen in this area. The $\Delta \sigma$ decreased at a decreasing rate in the models moving further away from the interface. With the increase in distance from TC-BC interface, the effect on the stresses due to the interface profile seems to be lower. However, in the case of S2 and B2 models, stresses initially decreased with increasing distance as other models but near the PL-DL interface, the stresses remained almost constant. The reason behind this could be the stress pattern generated due to the crack tips at the PLDL interface as shown in Fig. 12(b).

For all three sets of models developed in this study as described in section "Model Description", it can be clearly observed that the bilayer models B1-B3 had lower $\Delta \sigma$ than the single-layer models S1-S3. The bilayer models having the DL showed around $16 \% \Delta \sigma$ reduction near the peak areas when comparing $\mathrm{S} 1$ and $\mathrm{B} 1$. This result indicates that the bilayer topcoat microstructure is beneficial for increasing the thermal cyclic lifetime of SPS coatings as also concluded in previous work done on APS coatings.

It can be also observed in Fig. 13 that the models with vertical cracks down to the TC-BC interface had the lowest $\Delta \sigma$ of all coatings for both single-layer and bilayer TBCs. They had the lowest $\Delta \sigma$ as compared to the rest of the models through out the $Y$ direction distance. Near the peak location, around $40 \% \Delta \sigma$ reduction was observed when comparing S1 and S3. This result indicates that vertical cracks have a more significant effect on $\Delta \sigma$ than the DL, and thus are more beneficial for higher TBC lifetime. The most beneficial model was the bilayer model B3 with vertical cracks down to the TC-BC interface which had both beneficial effects from the DL as well as the vertical cracks.

When comparing the SEM images shown in Fig. 3(a) and 4(a), the models most accurately representing the experimental coatings are S3 and B3, respectively, as 
Fig. $12 X$ direction stresses in the models (a) S1 and (b) S2 at the end of the heating cycle

B: Static Structural

Dormal Stress - TBC

Type: Normal Stress (Xxis)

Unit: $\mathrm{MPa}$

Global Coordinate System

2016-12-16 08:23

110

102,77 Max

60

50

40

30

3

$-5,8303$ Min

(a)

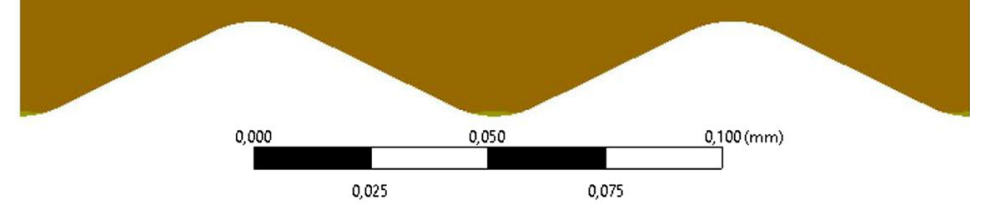

B: Static Structural

$X$ Axis - Normal Stress - TBC

Type: Normal Stress $(\times$ Axis $)$

Unit: $\mathrm{MPa}$

Global Coordinate System

Time: 375

2016-12-1608:21

$173,63 \operatorname{Max}$

\begin{tabular}{|l}
170 \\
170 \\
80 \\
60 \\
50 \\
40 \\
30 \\
20 \\
3
\end{tabular}

$3,0086 \mathrm{Min}$

(b)

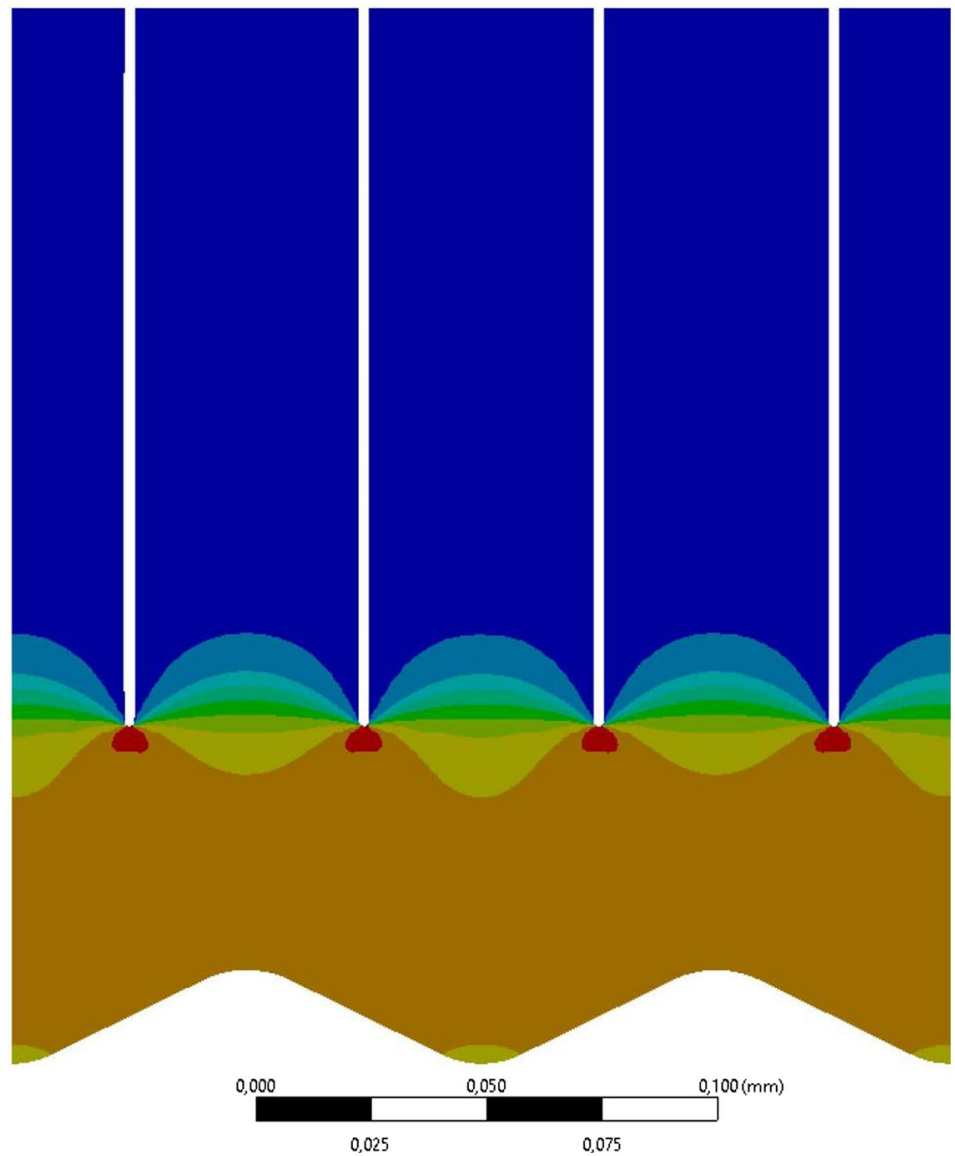


Fig. $13 Y$ direction stress amplitudes $(\Delta \sigma)$ in all models against the $Y$ direction distance from a peak of the TC-BC interface

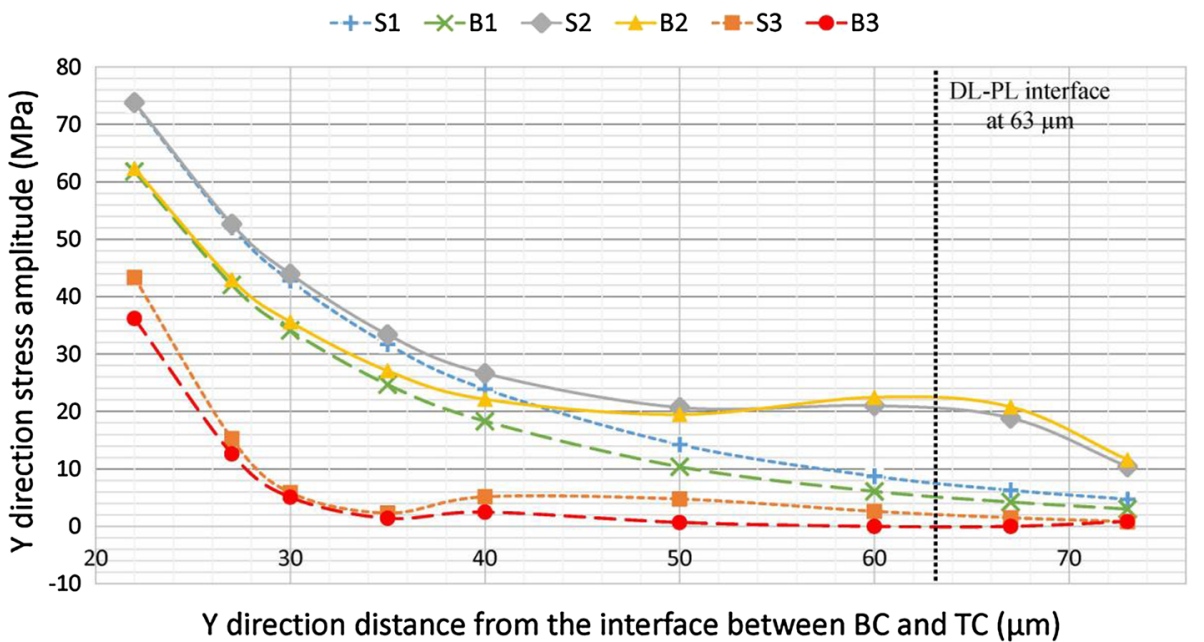

$Y$ direction distance from the interface between $B C$ and $T C(\mu \mathrm{m})$ both coatings had columnar gaps or vertical cracks down to the TC-BC interface (even if it was not initially intended for the bilayer system). It can be observed in Fig. 13 that B3 had a lower $\Delta \sigma$ than $\mathrm{S} 3$, which could explain the longer lifetime of the bilayer system in burner rig testing as per the lifetime prediction model proposed by Liu et al. (Ref 8).

\section{Conclusions}

In this study, a bilayer topcoat with a dense layer close to the topcoat-bondcoat interface followed by a porous columnar layer was fabricated by SPS and its lifetime under thermal shock testing was compared to the singlelayer porous columnar SPS topcoat in TBCs. The effect of the dense layer and column gaps/vertical cracks on the coating stresses under thermal shock loading conditions in single and bilayer TBC systems was studied by finite element modeling.

The experimental results showed that it was possible to achieve a bilayer topcoat by SPS as intended and the bilayer TBC exhibited significantly higher thermal shock lifetime as compared to the single-layer TBC. The failure in single-layer TBC occurred in the topcoat near the TC$\mathrm{BC}$ interface while in the bilayer $\mathrm{TBC}$, the failure was a mixture of cracking in the topcoat near the TC-BC interface and close to the PL-DL interface. The modeling results showed that both dense layer and vertical cracks/column gaps are beneficial to enhance TBC lifetime as they reduce the induced stresses during thermal shock loading. The modeling results could thus explain the longer lifetime of the bilayer TBC in burner rig testing.

A graded coating with denser microstructure near the TC-BC interface and porous microstructure toward the surface with column gaps/vertical throughout the topcoat could be beneficial to further extend TBC lifetime as it would not contain a clear interface between the porous and dense layer and thus preventing failure in the interface.

Acknowledgments The authors will like to acknowledge the help received from Kjell Niklasson at University West on simulation work and Stefan Björklund at University West for the spraying of samples.

Open Access This article is distributed under the terms of the Creative Commons Attribution 4.0 International License (http://crea tivecommons.org/licenses/by/4.0/), which permits unrestricted use, distribution, and reproduction in any medium, provided you give appropriate credit to the original author(s) and the source, provide a link to the Creative Commons license, and indicate if changes were made.

\section{References}

1. D.R. Clarke, M. Oechsner, and N.P. Padture, Thermal-Barrier Coatings for More Efficient Gas-Turbine Engines, MRS Bull., 2012, 37(10), p 891-898

2. L. Pawlowski, Suspension and Solution Thermal Spray Coatings, Surf. Coat. Technol., 2009, 203(19), p 2807-2829

3. P. Fauchais and G. Montavon, Latest Developments in Suspension and Liquid Precursor Thermal Spraying, J. Therm. Spray Technol., 2010, 19(1-2), p 226-239

4. L. Łatka, A. Cattini, L. Pawłowski, S. Valette, B. Pateyron, J.-P. Lecompte, R. Kumar, and A. Denoirjean, Thermal Diffusivity and Conductivity of Yttria Stabilized Zirconia Coatings Obtained by Suspension Plasma Spraying, Surf. Coat. Technol., 2012, 208, p 87-91

5. A. Ganvir, N. Curry, S. Bjorklund, N. Markocsan, and P. Nylen, Characterization of Microstructure and Thermal Properties of YSZ Coatings Obtained by Axial Suspension Plasma Spraying (ASPS), J. Therm. Spray Technol., 2015, 24(7), p 1195-1204

6. N. Curry, N. Markocsan, X.-H. Li, A. Tricoire, and M. Dorfman, Next Generation Thermal Barrier Coatings for the Gas Turbine Industry, J. Therm. Spray Technol., 2011, 20(1-2), p 108-115

7. J.R. Nicholls, K.J. Lawson, A. Johnstone, and D.S. Rickerby, Methods to Reduce the Thermal Conductivity of EB-PVD TBCs, Surf. Coat. Technol., 2002, 151-152, p 383-391 
8. Y. Liu, C. Persson, and J. Wigren, Experimental and Numerical Life Prediction of Thermally Cycled Thermal Barrier Coatings, $J$. Therm. Spray Technol., 2004, 13(3), p 415-424

9. R. Vaßen, S. Giesen, and D. Stöver, Lifetime of Plasma-Sprayed Thermal Barrier Coatings: Comparison of Numerical and Experimental Results, J. Therm. Spray Technol., 2009, 18(5-6), p 835-845

10. V. Viswanathan, G. Dwivedi, and S. Sampath, Engineered Multilayer Thermal Barrier Coatings for Enhanced Durability and Functional Performance, J. Am. Ceram. Soc., 2014, 97(9), p 2770-2778

11. X.L. Fan, R. Xu, W.X. Zhang, and T.J. Wang, Effect of Periodic Surface Cracks on the Interfacial Fracture of Thermal Barrier Coating System, Appl. Surf. Sci., 2012, 258, p 9816-9823

12. N. Curry, Z. Tang, N. Markocsan, and P. Nylén, Influence of Bond Coat Surface Roughness on the Structure of Axial Suspension Plasma Spray Thermal Barrier Coatings: Thermal and Lifetime Performance, Surf. Coat. Technol., 2015, 268, p 15-23

13. H. Kaßner, A. Stuke, M. Rödig, R. Vaßen, and D. Stöver, Influence of Porosity on Thermal Conductivity and Sintering in Suspension Plasma Sprayed Thermal Barrier Coatings, Adv. Ceram. Coat. Interfaces III, Ceram. Eng. Sci. Proc., 2009, 29(4), p 147

14. T.S. Hille, S. Turteltaub, and A.S.J. Suiker, Oxide Growth and Damage Evolution in Thermal Barrier Coatings, Eng. Fract. Mech., 2011, 78(10), p 2139-2152

15. M. Ranjbar-Far, J. Absi, and G. Mariaux, Finite Element Modeling of the Different Failure Mechanisms of a Plasma Sprayed Thermal Barrier Coatings System, J. Therm. Spray Technol., 2012, 21(6), p 1234-1244

16. J. Rösler, M. Bäker, and M. Volgmann, Stress State and Failure Mechanisms of Thermal Barrier Coatings: Role of Creep in Thermally Grown Oxide, Acta Mater., 2001, 49(18), p 3659-3670
17. A.G. Evans, D.R. Mumm, J.W. Hutchinson, G.H. Meier, and F.S. Pettit, Mechanisms Controlling the Durability of Thermal Barrier Coatings, Prog. Mater. Sci., 2001, 46(5), p 505-553

18. E.P. Busso, J. Lin, S. Sakurai, and M. Nakayama, A Mechanistic Study of Oxidation-Induced Degradation in a Plasma-Sprayed Thermal Barrier Coating System. Part I: Model Formulation, Acta Mater., 2001, 49(9), p 1515-1528

19. N. Curry, K. VanEvery, T. Snyder, and N. Markocsan, Thermal Conductivity Analysis and Lifetime Testing of Suspension Plasma-Sprayed Thermal Barrier Coatings, Coatings, 2014, 4, p $630-650$

20. M. Marr and O. Kesler, Permeability and Microstructure of Suspension Plasma-Sprayed YSZ Electrolytes for SOFCs on Various Substrates, J. Therm. Spray Technol., 2012, 21(6), p 1334-1346

21. K. VanEvery, M.J.M. Krane, R.W. Trice, H. Wang, W. Porter, M. Besser, D. Sordelet, J. Ilavsky, and J. Almer, Column Formation in Suspension Plasma-Sprayed Coatings and Resulting Thermal Properties, J. Therm. Spray Technol., 2011, 20(4), p 817-828

22. S. Mahade, N. Curry, S. Björklund, N. Markocsan, P. Nylén, and R. Vaßen, Functional Performance of $\mathrm{Gd}_{2} \mathrm{Zr}_{2} \mathrm{O}_{7} / \mathrm{YSZ}$ Multi-layered Thermal Barrier Coatings Deposited by Suspension Plasma Spray, Surf. Coat. Technol., 2016, doi:10.1016/j.surfcoat.2016. 12.062

23. M. Gupta, K. Skogsberg, and P. Nylén, Influence of TopcoatBondcoat Interface Roughness on Stresses and Lifetime in Thermal Barrier Coatings, J. Therm. Spray Technol., 2014, 23(1-2), p 170-181

24. C.M. Heveran, J. Xu, V.K. Sarin, and S.N. Basu, Simulation of Stresses in TBC-EBC Coating Systems for Ceramic Components in Gas Turbines, Surf. Coat. Technol., 2013, 235, p 354-360 